\title{
Phosphorylation of elF4E serine 209 is associated with tumour progression and reduced survival in malignant melanoma
}

\author{
Julia H Carter ${ }^{\star}, 1$, James A Deddens ${ }^{2}$, Nelson Reed Spaulding IV³, Denise Lucas ${ }^{1}$, Bruce M Colligan ${ }^{1}$, \\ Thomas Grant Lewis ${ }^{1}$, Elyse Hawkins ${ }^{1}$, Jordan Jones ${ }^{1}$, Jackson O Pemberton ${ }^{4}$, Larry E Douglass ${ }^{1}$ \\ and Jeremy R Graff 5 ,6
}

${ }^{1}$ Wood Hudson Cancer Research Laboratory, 931 Isabella Street, Newport, KY 41071, USA; ${ }^{2}$ Department of Mathematical Sciences, University of Cincinnati, 4512 French Hall, ML 25, Cincinnati, OH 45221, USA; ${ }^{3}$ Department of Pathology and Laboratory Medicine, University of Louisville School of Medicine, 627 South Preston Street, Louisville, KY 40292, USA; ${ }^{4}$ St Elizabeth Healthcare, Department of Laboratory Medicine, 20 Medical Village Drive, Edgewood, KY 41018, USA and ${ }^{5}$ Eli Lilly \& Company, Lilly Corporate Center, DC 0546, Indianapolis, IN 46285, USA

\begin{abstract}
Background: Melanoma is a disease that primarily arises in the skin but is a derivative of the neural crest. Eukaryotic translation initiation factor $4 \mathrm{E}$ (elF4E) regulates translation of multiple malignancy-associated mRNAs and is overexpressed in many epithelial tumours. However, expression in human tumours derived from the neural crest is unknown. Here, we determined the association of elF4E and phospho-elF4E expression in melanocytic lesions with malignant conversion, metastatic potential and patient survival.
\end{abstract}

Methods: Archived formalin-fixed, paraffin-embedded surgical specimens from 114 patients with melanocytic lesions were stained immunohistochemically for elF4E and phospho-elF4E and evaluated semiquantitatively. The relationship between cytoplasmic and nuclear elF4E and phospho-elF4E protein expression, melanocytic lesion subtype and tumour progression was determined. Kaplan-Meier survival analyses and Cox proportional hazard regression were performed.

Results: Increased eIF4E and phospho-elF4E expression was highly associated with malignancy $(P<0.0001)$. High nuclear phospho-elF4E was associated with synchronous or future metastasis $(P=0.0059)$. Kaplan-Meier analyses demonstrated highly significant associations between high histoscores for cytoplasmic and nuclear phospho-elF4E and reduced survival in all patients $(P=0.0003$ and 0.0009 , respectively).

Conclusions: Increased melanoma expression of elF4E and phospho-elF4E is associated with metastatic potential, reduced survival and increased risk of death.

Malignant melanoma continues to be a challenge both in terms of understanding the biologic mechanisms behind its behaviour and applying that information toward developing new therapeutic interventions. Although malignant melanoma represents only $5 \%$ of all skin cancers, it is responsible for $80 \%$ of all skin cancer- related deaths (Linos et al, 2009; Siegel et al, 2014). In 2012 alone, an estimated 232000 new cases of invasive melanoma and 55000 deaths occurred globally (Lian and Mihm, 2014). The high death rate in melanoma is attributable to the high metastatic potential of melanoma and resistance to apoptosis. Five-year survival rate with 
metastatic melanoma is only $5-16 \%$ compared with a $90 \%$ survival rate in patients with early-stage, localised melanoma (Soengas and Lowe, 2003; Gray-Schopfer et al, 2007; Linos et al, 2009; Siegel et al, 2014), highlighting the need to understand tumour progression in melanoma to enable development of novel effective therapies.

Although melanoma is a disease that primarily arises in the skin, it is a derivative of the neural crest. During embryogenesis, an epithelial-to-mesenchymal transition occurs to form these cells. Once formed, neural crest cells migrate to various body locations and differentiate into cells of the central and peripheral nervous system, cells of the adrenal medulla, various craniofacial connective tissues and melanocytes (Duband et al, 1995; Gilbert, 2000). The histopathologic progression in melanocytic transformation is described as follows (Chin et al, 1998): (1) normal skin has an even distribution of dendritic melanocytes throughout the basal layer; (2) benign proliferation of melanocytes - in a nevus, nevoid melanocytes are organised into uniform nests of cells; (3) melanocyte dysplasia - a dysplastic nevus has irregular and bridging nests of cells consisting of large atypical melanocytes; (4) in situ melanoma, radial growth phase (RGP) - single dysplastic cells are present in the epidermis (Pagetoid spread); (5) malignant melanoma, the vertical growth phase (VGP). Clark level of invasion and Breslow thickness have a strong predictive value in the prognosis of patients with non-metastatic melanomas. Most VGP, tumorigenic, melanomas evolve within an RGP plaque. The VGP, unlike the RGP, is associated with a chance for distant metastasis. Nodular melanomas (NMs) evolve directly from apparently normal skin to VGP. Approximately $45 \%$ of new melanoma cases are entirely in the RGP, $10 \%$ are in the VGP alone and the remaining $45 \%$ have a VGP tumour nodule surrounded by an RGP plaque (Elder and Murphy, 2010). The RGP subtypes include: superficial spreading melanoma (SSM), lentigo maligna melanoma, acral lentiginous melanoma (LM) and mucosal LM. Superficial spreading melanomas represent 70\%, NMs represent $10-30 \%$ and LMs $\sim 5 \%$ of all melanomas (Chin et al, 1998). An association between genetic alterations and morphologic findings supports the existence of biologically distinct melanoma subtypes and stages of melanoma progression (Haqq et al, 2005; Jaeger et al, 2007).

Targeting translation has been suggested as a novel strategy for therapy of malignancies originating in the epithelium (Graff et al, 1995, 2007, 2008, 2009; Silvera et al, 2010). Eukaryotic translation initiation factor $4 \mathrm{E}$ regulates the translation of multiple malignancy-associated mRNAs. Eukaryotic translation initiation factor $4 \mathrm{E}$ is overexpressed in many human and experimental tumours. Reducing eIF4E expression reduces tumour growth and metastases. Eukaryotic translation initiation factor $4 \mathrm{E}$ is released from the translation inhibitor 4E-BP1 upon hyperphosphorylation of 4EBP1 by mTOR (Gingras et al, 1999). Phosphorylation of 4E-BP1 is associated with poor survival in melanoma patients (O'Reilly et al, 2009), suggesting that increased translation initiation may be a common event in melanoma and is associated with poor prognosis. In $\mathrm{BRAF}^{\mathrm{V} 600 \mathrm{E}}$ melanoma cell lines, the chemotherapeutic agent vemurafenib inhibits $4 \mathrm{E}-\mathrm{BP} 1$ phosphorylation. In cells with an acquired resistance to vemurafenib, there is an increased dependence on eIF4E for cell survival (Zhan et al, 2015).

Although phosphorylation of $4 \mathrm{E}-\mathrm{BP} 1$ releases eIF4E, eIF4E is further activated by phosphorylation downstream of the Mnk 1 and 2 kinases (Waskiewicz et al, 1999). The role of eIF4E phosphorylation in transformation and histopathologic progression of melanocytes to melanomas has not been reported previously. However, inhibition of eIF4E phosphorylation by the Mnk inhibitor cercosporamide reduces the outgrowth of B16 lung metastases in mice in vivo and at concentrations that effectively inhibit eIF4E phosphorylation, blocks cell proliferation, anchorageindependent growth and elicits apoptosis in B16 melanoma cells in vitro (Konicek et al, 2011). Western blot data indicate that phospho-eIF4E as well as eIF4E are found in seven melanoma cell lines including N-RAS and BRAF/PTEN mutant melanoma cell lines (O'Reilly et al, 2009). More than 50\% of human melanomas have BRAF mutations and another $20 \%$ show N-RAS mutations (Bastian, 2014). Both would be expected to elevate Mnk activity and by extension eIF4E phosphorylation.

These data suggested the hypothesis that eIF4E phosphorylation is important in the development of human malignant melanoma, in melanoma progression to metastasis and signals increased risk of death from melanoma. If so, inhibition of eIF4E phosphorylation may be a novel target for melanoma therapy. We addressed this hypothesis by semiquantitative immunohistochemical (IHC) evaluation of eIF4E and phospho-eIF4E expression in archived surgical specimens of multiple subtypes of melanocytic lesions in patients in relation to their clinical outcome and death. We determined that phospho-eIF4E was associated with malignancy and was increased in subtypes of melanoma with increased metastatic potential. Elevated phospho-eIF4E was prognostic of reduced patient survival and associated with increased risk of death from melanoma. Taken together, these data validate in surgical specimens of human malignant melanomas the numerous experimental studies of the role of translation in cancer development and metastatic progression (Pelletier et al, 2015). Our data give evidence that elevated phosphorylation of eIF4E serine 209 in surgical specimens is associated with malignancy, metastases and reduced survival in malignant melanoma and suggest that inhibition of eIF4E phosphorylation may be a novel approach to therapy of human malignant melanoma.

\section{MATERIALS AND METHODS}

Tissues studied. Archived, formalin-fixed, paraffin-embedded (FFPE) tissues were donated to Wood Hudson Cancer Research Laboratory by St Elizabeth Healthcare in Northern Kentucky and are preserved in the environmentally controlled Wood Hudson Biospecimen Repository. The study had the approval of the St Elizabeth Healthcare Institutional Review Board and Wood Hudson Cancer Research Laboratory has an HIPAA waiver from St Elizabeth Healthcare.

A total of 149 archived FFPE surgical specimens from 114 patients obtained at surgeries performed between 1981 and 2006 were stained and evaluated. Melanocytic lesions were classified according to the subtype in H\&E-stained histologic sections by a Board Certified pathologist (LED). Included in the study were 23 patients with 35 dermal, compound or junctional nevi, 34 patients with SSM, 21 patients with 22 LMs, 16 patients with NM and 20 patients with 42 dermal, lymph node or visceral metastases (metastatic melanoma (MM)) (Table 1).

Clinical follow-up was obtained from Tumour Registries with the assistance of Tumour Registrars at St Elizabeth Healthcare. Survival information was available for up to 30 years.

Immunohistochemistry. Air-dried $5-\mu \mathrm{m}$ paraffin sections were dewaxed in Clearite, and rehydrated through a graded series of alcohols to distilled water. They were placed in tris-buffered saline (TBS) containing $0.05 \%$ Tween. Following rehydration, antigen retrieval was with $0.1 \mathrm{M}$ citrate buffer, $\mathrm{pH} 6.0$, heated to $95^{\circ} \mathrm{C}$ in a water bath for $20 \mathrm{~min}$. Sections were allowed to cool for $20 \mathrm{~min}$, and then rinsed in deionised water and placed in TBS-Tween. Adjacent sections were stained immunohistochemically for the expression of eIF4E with a mouse monoclonal antibody (BD Biosciences, New York, NY, USA; cat. no.: 610270, $1.67 \mathrm{mg} \mathrm{ml}^{-1}$ ) or mouse IgG2B control (Dako, Carpinteria, CA, USA; cat. no.: X0931, $1.67 \mathrm{mg} \mathrm{ml}^{-1}$ ) and phosphorylated eIF4E with a rabbit monoclonal antibody (Novus Biologicals, Littleton, CO, USA; 
Table 1. Tissues studied: Melanocytic lesion histopathologic subtype, patient gender, age and death from melanoma

\begin{tabular}{|c|c|c|c|c|c|c|c|}
\hline Lesion subtype & $\begin{array}{l}\text { No. of } \\
\text { lesions }\end{array}$ & $\begin{array}{l}\text { No. of } \\
\text { males }\end{array}$ & $\begin{array}{l}\text { No. of } \\
\text { females }\end{array}$ & $\begin{array}{l}\text { Av. age } \\
\text { males }\end{array}$ & $\begin{array}{l}\text { Av. age } \\
\text { females }\end{array}$ & $\begin{array}{l}\text { No. died of } \\
\text { melanoma }\end{array}$ & $\begin{array}{l}\text { No. in survival } \\
\text { study }\end{array}$ \\
\hline $\begin{array}{l}\text { Nevi } \\
\text { Dermal nevi } \\
\text { Compound nevi } \\
\text { Junctional nevi }\end{array}$ & $\begin{array}{r}35 \\
21 \\
11 \\
3\end{array}$ & $\begin{array}{r}11 \\
8 \\
2 \\
2\end{array}$ & $\begin{array}{r}12 \\
5 \\
6 \\
1\end{array}$ & $\begin{array}{l}37.5 \pm 5.7 \\
40.4 \pm 6.5 \\
19.0 \pm 10.0 \\
40.0 \pm 12.0\end{array}$ & $\begin{array}{c}33.5 \pm 4.3 \\
36.8 \pm 5.1 \\
32.7 \pm 7.7 \\
22.0\end{array}$ & $\begin{array}{l}0 \\
0 \\
0 \\
0\end{array}$ & $\begin{array}{l}0 \\
0 \\
0 \\
0\end{array}$ \\
\hline SSM & 34 & 17 & 17 & $54.8 \pm 3.1$ & $53.1 \pm 4.4$ & 7 & 34 \\
\hline $\begin{array}{l}\text { LM } \\
\text { Acral lentiginous melanoma } \\
\text { Lentigo maligna melanoma } \\
\text { Mucosal lentiginous melanoma }\end{array}$ & $\begin{array}{r}22 \\
6 \\
13 \\
3\end{array}$ & $\begin{array}{r}10 \\
3 \\
6 \\
1\end{array}$ & $\begin{array}{r}11 \\
3 \\
6 \\
2\end{array}$ & $\begin{array}{l}71.2 \pm 4.2 \\
77.0 \pm 4.2 \\
67.8 \pm 6.5 \\
74.0\end{array}$ & $\begin{array}{l}68.4 \pm 5.2 \\
71.7 \pm 1.5 \\
66.7 \pm 8.0 \\
68.5 \pm 22.5\end{array}$ & $\begin{array}{l}7 \\
2 \\
3 \\
2\end{array}$ & $\begin{array}{r}20 \\
6 \\
11 \\
3\end{array}$ \\
\hline NM & 16 & 8 & 8 & $53.3 \pm 8.8$ & $62.6 \pm 4.8$ & 12 & 14 \\
\hline $\begin{array}{l}\text { MM } \\
\text { Dermal metastases } \\
\text { Lymph node metastases } \\
\text { Distant metastases } \\
\text { Clark level I and II } \\
\text { Clark level } \geqslant \text { III }\end{array}$ & $\begin{array}{r}42 \\
7 \\
28 \\
7 \\
23 \\
44\end{array}$ & $\begin{array}{r}13 \\
5 \\
15 \\
5 \\
8 \\
25\end{array}$ & $\begin{array}{r}7 \\
0 \\
5 \\
2 \\
15 \\
17\end{array}$ & $\begin{array}{l}55.1 \pm 2.9 \\
56.0 \pm 5.7 \\
55.7 \pm 3.7 \\
57.4 \pm 7.0 \\
51.9 \pm 4.6 \\
60.2 \pm 3.6\end{array}$ & $\begin{array}{l}59.1 \pm 4.9 \\
59.0 \pm 6.3 \\
59.5 \pm 10.5 \\
58.3 \pm 5.3 \\
587 \pm 3.6\end{array}$ & $\begin{array}{r}14 \\
1 \\
11 \\
1 \\
3 \\
15\end{array}$ & $\begin{array}{r}20 \\
2 \\
14 \\
3 \\
23 \\
23 \\
40\end{array}$ \\
\hline
\end{tabular}

cat. no. NB 100-79938, $1.42 \mathrm{mg} \mathrm{ml}^{-1}$ ) or rabbit IgG control (Dako; cat. no.: X0903, $1.42 \mathrm{mg} \mathrm{ml}^{-1}$ ) for 60 min using a Dako autostainer and the Dako LSAB2 staining system (Dako) with diaminobenzidine as chromagen. Antibody specificity was established as reported previously (Graff et al, 2007, 2009; Furic et al, 2010; Hong et al, 2011; Konicek et al, 2011). Immunohistochemically stained sections were counterstained with methyl green, dehydrated in butanol and Clearite and coverslipped with Permount (Fisher Healthcare, Hanover Park, IL, USA). A slide from a single case was included in every IHC run as a staining control along with a buffer control.

Immunohistochemically stained sections were evaluated semiquantitatively by two observers (LED and JHC or NRS) using a Nikon Coolscope (Nikon Instruments, Inc., New York, NY, USA). Histoscores (HS) were calculated from the intensity of the stain and the area of the epithelium stained ( $\mathrm{HS}=$ intensity $\times$ area). Intensity was negative $(0)$, trace $(0.5)$, light $(1+)$, moderate $(2+)$ or intense $(3+)$. Area was negative $(0), 1-25 \%$ stained $(0.1), 26-$ $50 \%$ stained $(0.4), 51-75 \%$ stained $(0.6)$ or $76-100 \%$ stained $(0.9)$. Cytoplasmic stain and nuclear stain were recorded separately. Observers were blinded to patient outcome.

Study design. This was a retrospective study in which melanoma cases were selected from tumour registries without the knowledge of melanoma subtype or clinical outcome. Clinical information obtained as part of the study included patient age and gender, date of diagnosis, stage of disease, depth of invasion (Clark level), date of recurrence, site of metastases, date of death (or date known to be alive) and if death was due to melanoma. Variables analysed were cytoplasmic and nuclear HS for eIF4E and phospho-eIF4E, subtype of melanocytic lesion, age, depth of invasion and survival.

Statistical analyses. The data consist of 149 specimens, from 114 patients, with follow-up data on 88 patients. Means and standard errors were computed for age, and for all markers by tissue type. Data analysis included $t$-tests, nonparametric Wilcoxon's tests and repeated-measures ANOVA (to account for multiple observations per patients). For those patients with follow-up information, Kaplan-Meier survival analyses were performed with log-rank statistics, and Cox proportional hazard regression were performed using IHC HS data for cytoplasmic or nuclear eIF4E staining and cytoplasmic or nuclear phospho-eIF4E. The 75th percentile of staining, expressed as HS for each marker in the 88 patients used in the survival analysis, was chosen a priori as the cut-point for the Kaplan-Meier analyses. The proportional hazards Cox model was used to determine the hazard ratios (HRs) adjusted for age and lesion histopathologic subtype. The Cox model was also used to analyse the continuous raw scores for all markers. All analyses were carried out using SAS 9.3 (SAS Institute, Inc., Cary, NC, USA).

\section{RESULTS}

Histopathologic subtypes of cutaneous melanoma and patient characteristics determine survival. Human melanoma is a heterogeneous disease. We studied the three major histopathologic subtypes of primary cutaneous melanoma (Figure 1) as well as metastatic melanoma to characterise differences in patient survival based on melanoma subtype and patient age and gender.

Superficial spreading melanoma. Superficial spreading melanomas is the most frequent histopathologic type of melanoma encountered (Figure 1A). It begins with an RGP in the epidermis, characterised by the presence of individual melanoma cells and clusters of melanoma cells in both the deep and in the more superficial layers of the epidermis. This RGP may be followed by a VGP during which the melanoma infiltrates into all layers of the dermis and into the subcutaneous tissue.

The LMs: acral LM, mucosal LM and lentigo maligna melanoma. These three melanomas have one thing in common histopathologically; the RGP is almost entirely limited to the basal layer of the epidermis (Figure 1B). This RGP may be followed by a VGP extending into the dermis and subcutaneous tissue. These three LMs differ in the sites in which they arise. Acral LMs arise on the distal extremities. Mucosal LMs are found at sites not ordinarily exposed to sunlight. Lentigo maligna melanomas arise in the skin more commonly associated with exposure to sunlight.

Nodular melanoma. Nodular melanomas are the second most frequent histopathologic type of melanoma and are associated with the greatest mortality (Figure 1C). The tumours appear to arise in the dermis, unassociated with the overlying epidermis. Even when the melanoma is seen to be immediately below the epidermis, and even to touch it, the two appear to remain separate. The NM has only a VGP. It appears to be unassociated with an RGP and is associated with a chance for distant metastasis.

We found that patient age and melanoma subtype determined survival. Average age of patients with benign nevi $(37 \pm 3)$ was 
A

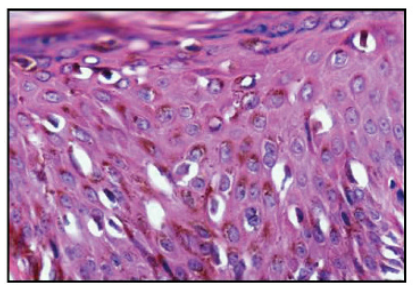

B

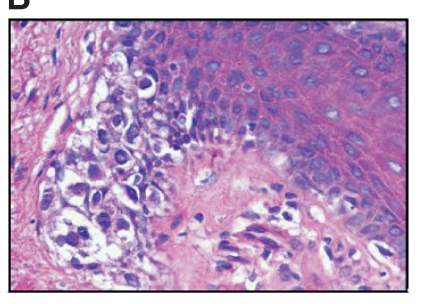

C

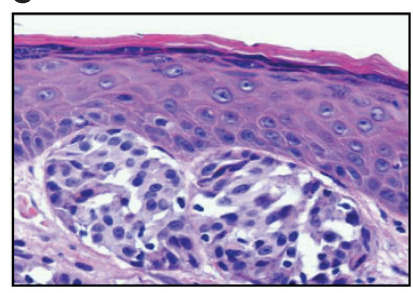

D

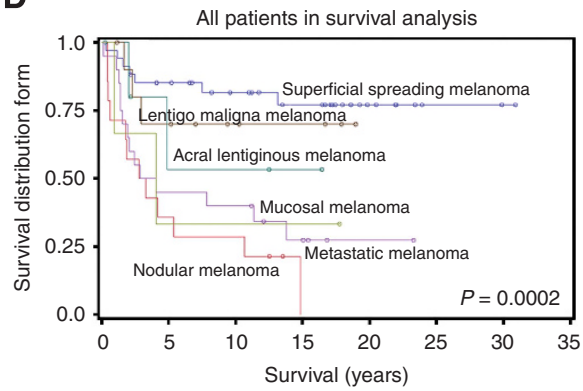

$\mathbf{E}$

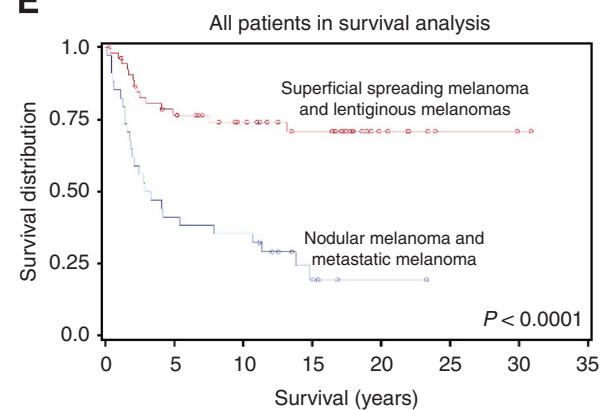

Figure 1. Melanocytic lesion histopathologic subtypes and survival. (A) Superficial spreading melanoma, $\times 400$, haematoxylin and eosin (H\&E) stain. (B) Lentiginous melanoma, $\times 400, \mathrm{H} \& \mathrm{E}$ stain. (C) Nodular melanoma, $\times 400, \mathrm{H} \& E$ stain. (D) Patient survival is related to melanocytic lesion histopathologic subtype. Survival is better in SSM $>$ LM $>M M>N M$. (E) Patients with SSM and LM have better survival than patients with NM and MM.

significantly younger compared with that of patients with malignant melanoma $(P=0.0001)$. Average age of patients with SSM (54 \pm 3$)$, NM $(58 \pm 5)$ and metastases $(53 \pm 2)$ was younger compared with that of patients with LM $(70 \pm 3)(P=0.0004)$. Male and female patients were of similar ages for each lesion type (Table 1).

Although statistical analyses found that age was a confounding factor for survival, younger patients had a poorer outcome. The age difference in survival was a consequence of the difference in lethality between the malignant melanoma subtypes (Figure 1D). Survival in patients with RGP melanoma subtypes (SSM and LM) differed significantly from patients with NMs or MMs $(P<0.0001$; Figure $1 \mathrm{E}$ ). Whereas $75 \%$ of patients with $\mathrm{NM}$ and $70 \%$ of patients with MM died, only $21 \%$ of patients with SSM and $33 \%$ of patients with LM died from melanoma (Table 1). Consistent with this observation, the depth of invasion as assessed by Clark level was related to survival as $13 \%$ of patients with Clark level I and II died compared with $36 \%$ of patients with Clark level III, IV or V tumours.

Increased eIF4E and phospho-eIF4E expressions are associated with malignancy. Immunohistochemical detection of eIF4E and phospho-eIF4E expression was assessed in the cytoplasm and nucleus of 149 specimens of melanocytic lesions from 114 patients (Table 2A-C). Uniformly high expression of eIF4E and phosphoeIF4E was seen in nearly all individual malignant melanocytes, whereas light to moderate staining was scattered in occasional cells within benign nevi (Figure 2). All but two melanocytic lesions (99\%) had eIF4E cytoplasmic stain and all but five lesions (97\%) stained positively for nuclear eIF4E. Only one melanocytic lesion did not have cytoplasmic phospho-eIF4E expression. However, nuclear phospho-eIF4E was absent in $24 \%$ of the specimens (35 lesions), including 26 of 36 nevi (72\%) and 5 of 45 RGP lesions (11\%), suggesting an association between malignancy and expression of nuclear phosph-eIF4E. Indeed, both cytoplasmic and nuclear expression of eIF4E and phosphoeIF4E were significantly increased in all malignant melanomas compared with benign nevi $(P<0.0001$ for all markers by both ANOVA and nonparametric tests) (Table 2A and B and Figure $2 \mathrm{~A}$ and $\mathrm{B}$ ).

Significant differences were found in cytoplasmic expression of eIF4E and phospho-eIF4E between dermal, compound and junctional nevi ( $P=0.0324$ and 0.0012 , respectively, by ANOVA) with junctional nevi having marginally or significantly higher expression $(P=0.0645$ and 0.0011 , respectively).

Nuclear phospho-eIF4E was related to depth of invasion of superficial spreading melanomas assessed by Clark level, nuclear $\mathrm{HS}=0.19 \pm 0.05$ for 21 Clark level I and II lesions $v s 0.54 \pm 0.07$ for Clark level $\geqslant$ III $(P=0.0010$ by ANOVA, $P=0.0006$ by nonparametric tests). Correlation analysis showed that Clark level was significantly associated with nuclear phospho-eIF4E $(P=0.001)$ but not with any other variable (Table 2C). Nuclear expression of phospho-eIF4E was also highly associated with patient's age $(P=0.002)$ and lesion subtype $(P<0.0001)$. Highly significant correlations between nuclear and cytoplasmic phospho-eIF4E and nuclear and cytoplasmic eIF4E with patient's age and lesion subtype were also found (Table 2C). Age and lesion subtype were highly correlated $(P=0.0002)$.

Increased eIF4E and phospho-eIF4E expression are associated with metastatic potential. Superficial spreading melanoma and LM in the RGP do not have metastatic potential, whereas SSM and LM in the VGP and NM have metastatic potential. We asked if eIF4E and phospho-eIF4E expression differed in the RGP compared with the VGP. In 28 RGP vs 19 VGP melanomas significant increases occurred in the VGP in the expression of cytoplasmic eIF4E (HS 2.271 vs 1.772, $P=0.0207$ ), cytoplasmic phospho-eIF4E (HS 2.021 vs 1.508, $P=0.0080$ ) and nuclear phospho-eIF4E (HS 0.693 vs $0.329, P=0.0029$ ).

Melanomas in an RGP had significantly less cytoplasmic eIF4E (HS 1.772 vs 2.240, $P=0.0381$ ) and significantly less nuclear phospho-eIF4E (HS 0.329 vs $0.646, \quad P=0.0249$ ) compared with NM. Significant differences in eIF4E and phospho-eIF4E expression were not found in melanomas in a VGP compared with NMs, both of which have metastatic potential. 
Table 2A. Immunohistochemically detected 4E and p4E expression ${ }^{2}$

\begin{tabular}{|c|c|c|c|c|c|c|c|c|c|}
\hline Lesion subtype & $\begin{array}{l}\text { No. of } \\
\text { lesions }\end{array}$ & $\begin{array}{c}\text { 4E cyto HS } \\
\text { No. }\end{array}$ & $\begin{array}{l}\text { 4E cyto HS } \\
\text { Mean } \pm \text { s.e. }\end{array}$ & $\begin{array}{c}\text { 4E nuc HS } \\
\text { No. }\end{array}$ & $\begin{array}{l}\text { 4E nuc HS } \\
\text { Mean } \pm \text { s.e. }\end{array}$ & $\begin{array}{c}\text { p4E cyto HS } \\
\text { No. }\end{array}$ & $\begin{array}{l}\text { p4E cyto HS } \\
\text { Mean } \pm \text { s.e. }\end{array}$ & $\begin{array}{c}\text { p4E nuc HS } \\
\text { No. }\end{array}$ & $\begin{array}{l}\text { p4E nuc HS } \\
\text { Mean } \pm \text { s.e. }\end{array}$ \\
\hline Nevi & 35 & 35 & $1.07 \pm 0.12$ & 35 & $0.25 \pm 0.03$ & 34 & $0.41 \pm 0.06$ & 34 & $0.04 \pm 0.02$ \\
\hline Dermal nevi & 21 & 21 & $0.93 \pm 0.13$ & 21 & $0.26 \pm 0.03$ & 21 & $0.28 \pm 0.06$ & 21 & $0.04 \pm 0.02$ \\
\hline Compound nevi & 11 & 11 & $1.14 \pm 0.21$ & 11 & $0.27 \pm 0.06$ & 10 & $0.50 \pm 0.14$ & 10 & $0.04 \pm 0.04$ \\
\hline Junctional nevi & 3 & 3 & $2.03 \pm 0.34$ & 3 & $0.22 \pm 0.20$ & 3 & $1.06 \pm 0.16$ & 3 & $0.03 \pm 0.02$ \\
\hline SSM & 34 & 34 & $2.18 \pm 0.09$ & 34 & $0.70 \pm 0.09$ & 32 & $1.62 \pm 0.13$ & 32 & $0.34 \pm 0.06$ \\
\hline LM & 22 & 22 & $1.93 \pm 0.14$ & 22 & $0.60 \pm 0.08$ & 19 & $1.56 \pm 0.13$ & 19 & $0.34 \pm 0.08$ \\
\hline Acral lentiginous melanoma & 6 & 6 & $2.21 \pm 0.40$ & 6 & $0.92 \pm 0.19$ & 5 & $1.82 \pm 0.13$ & 5 & $0.38 \pm 0.09$ \\
\hline Lentigo maligna melanoma & 13 & 13 & $1.69 \pm 0.11$ & 13 & $0.47 \pm 0.08$ & 11 & $1.51 \pm 0.18$ & 11 & $0.36 \pm 0.13$ \\
\hline Mucosal lentiginous melanoma & 3 & 3 & $2.40 \pm 0.30$ & 3 & $0.34 \pm 0.17$ & 3 & $1.34 \pm 0.47$ & 3 & $0.24 \pm 0.22$ \\
\hline NM & 16 & 15 & $2.24 \pm 0.14$ & 15 & $0.72 \pm 0.10$ & 16 & $1.80 \pm 0.24$ & 16 & $0.65 \pm 0.13$ \\
\hline MM & 42 & 40 & $2.39 \pm 0.06$ & 40 & $0.86 \pm 0.07$ & 42 & $1.86 \pm 0.12$ & 42 & $0.55 \pm 0.07$ \\
\hline Dermal metastases & 7 & 6 & $2.18 \pm 0.27$ & 6 & $1.11 \pm 0.14$ & 7 & $1.57 \pm 0.32$ & 7 & $0.61 \pm 0.16$ \\
\hline Lymph node metastases & 28 & 28 & $2.46 \pm 0.06$ & 28 & $0.87 \pm 0.08$ & 28 & $1.94 \pm 0.14$ & 28 & $0.51 \pm 0.08$ \\
\hline Distant metastases & 7 & 6 & $2.31 \pm 0.18$ & 6 & $0.56 \pm 0.07$ & 7 & $1.86 \pm 0.34$ & 7 & $0.68 \pm 0.19$ \\
\hline Clark level I and II & 23 & 23 & $1.98 \pm 0.11$ & 23 & $0.70 \pm 0.13$ & 21 & $1.47 \pm 0.15$ & 21 & $0.19 \pm 0.05$ \\
\hline Clark level $\geqslant I I I$ & 44 & 44 & $2.16 \pm 0.09$ & 44 & $0.71 \pm 0.06$ & 42 & $1.73 \pm 0.12$ & 42 & $0.54 \pm 0.07$ \\
\hline
\end{tabular}

Abbreviations: $4 \mathrm{E}=$ cytoplasmic and nuclear eukaryotic translation initiation factor $4 \mathrm{E}$; elF4E = eukaryotic translation initiation factor $4 \mathrm{E}$; $\mathrm{HS}=$ histoscores; $\mathrm{LM}=$ lentiginous melanomas; $\mathrm{MM}=$ metastatic melanoma; $\mathrm{NM}=$ nodular melanoma; $\mathrm{p} 4 \mathrm{E}=$ phosphorylated eukaryotic translation initiation factor $4 \mathrm{E} ; \mathrm{SSM}=$ superficial spreading melanoma.

a In benign nevi and malignant melanoma histopathologic subtypes and MM expressed as HS = area stained $\times$ intensity of stain.

Table 2B. Statistical analyses (ANOVA and nonparametric $P$-values) of differences in immunohistochemically detected 4E and p4E expression ${ }^{2}$

\begin{tabular}{|c|c|c|c|c|}
\hline$P$-values & $\begin{array}{c}\text { 4E } \\
\text { cytoplasmic } \\
\text { HS }\end{array}$ & $\begin{array}{c}\text { 4E } \\
\text { nuclear } \\
\text { HS }\end{array}$ & $\begin{array}{c}\text { p4E } \\
\text { cytoplasmic } \\
\text { HS }\end{array}$ & $\begin{array}{c}\text { p4E } \\
\text { nuclear } \\
\text { HS }\end{array}$ \\
\hline \multicolumn{5}{|c|}{ Dermal/compound/junctional nevi } \\
\hline ANOVA & 0.0324 & 0.9337 & 0.0012 & 0.9907 \\
\hline Nonparametric & 0.0775 & 0.7618 & 0.0094 & 0.5241 \\
\hline \multicolumn{5}{|c|}{ Nevi vs melanomas } \\
\hline ANOVA & $<0.0001$ & $<0.0001$ & $<0.0001$ & $<0.0001$ \\
\hline Nonparametric & $<0.0001$ & $<0.0001$ & $<0.0001$ & $<0.0001$ \\
\hline \multicolumn{5}{|c|}{ Clark level I, II vs $\geqslant$ III } \\
\hline ANOVA & 0.2418 & 0.9298 & 0.2063 & 0.0010 \\
\hline Nonparametric & 0.1588 & 0.3503 & 0.1676 & 0.0006 \\
\hline \multicolumn{5}{|c|}{$\begin{array}{l}\text { Abbreviations: } \mathrm{ANOVA}=\text { analysis of variance; } 4 \mathrm{E}=\text { cytoplasmic and nuclear eukaryotic } \\
\text { translation initiation factor } 4 \mathrm{E} ; \text { elF } 4 \mathrm{E}=\text { eukaryotic translation initiation factor } 4 \mathrm{E} ; \mathrm{HS}= \\
\text { histoscores; } \mathrm{p} 4 \mathrm{E}=\text { phosphorylated eukaryotic translation initiation factor } 4 \mathrm{E} \text {. } \\
\mathrm{a}_{\text {In benign nevi and malignant melanoma histopathologic subtypes and metastatic }} \\
\text { melanoma expressed as } \mathrm{HS}=\text { area stained } \times \text { intensity of stain. }\end{array}$} \\
\hline
\end{tabular}

Dermal, lymph node and distant metastases were evaluated for differences in eIF4E and phospho-eIF4E expression (Table 2A). All metastases irrespective of metastatic site had similar eIF4E and phospho-eIF4E expression. Metastatic lesions had increased eIF4E and phospho-eIF4E expression relative to both benign nevi $(P<0.0001$, all markers $)$ and melanomas in an RGP $(P=0.0073$ eIF4E cytoplasmic, $P=0.0092$ eIF4E nuclear, $P=0.0401$ phospho-eIF4E cytoplasmic and $P=0.0138$ phospho-eIF4E nuclear). Melanoma metastases did not differ in eIF4E and phospho-eIF4E expression from NMs $(P>0.9$, all markers).

Follow-up of patients with primary tumours, including eight NMs, four LMs, and three SSMs, who subsequently developed metastases, or who had synchronous metastases indicated that those primary tumours with high nuclear phospho-eIF4E frequently metastasised $(P=0.0059)$. The means and medians for eIF4E and phospho-eIF4E in the primary tumour or regional metastases in patients who later developed either regional or distant metastases were greater than the means and medians of all patients with melanocytic lesions. Expression of eIF4E or phosphoeIF4E in tumours from patients with melanocytic lesions who
Table 2C. Correlation coefficients between patient age, melanocytic lesion histopathologic subtype, Clark level, and immunohistochemically detected 4E and p4E expression ${ }^{2}$

\begin{tabular}{|c|c|c|c|}
\hline & Age & Lesion subtype & Clark level \\
\hline \multicolumn{4}{|l|}{ Age } \\
\hline Correlation coefficient & - & 0.305 & 0.838 \\
\hline$P$-value & - & 0.0002 & 0.500 \\
\hline$N$ & - & 149 & 67 \\
\hline \multicolumn{4}{|l|}{ Tissue } \\
\hline Correlation coefficient & 0.305 & - & -0.046 \\
\hline$P$-value & 0.0002 & - & 0.715 \\
\hline N & 149 & - & 67 \\
\hline \multicolumn{4}{|l|}{ Clark level } \\
\hline Correlation coefficient & 0.838 & -0.046 & - \\
\hline$P$-value & 0.500 & 0.715 & - \\
\hline N & 67 & 67 & - \\
\hline \multicolumn{4}{|c|}{ elF4E cytoplasmic histoscore } \\
\hline Correlation coefficient & 0.251 & 0.442 & 0.126 \\
\hline$P$-value & 0.002 & $<0.0001$ & 0.309 \\
\hline$N$ & 146 & 147 & 67 \\
\hline \multicolumn{4}{|c|}{ elF4E nuclear histoscore } \\
\hline Correlation coefficient & 0.187 & 0.319 & 0.009 \\
\hline$P$-value & 0.024 & $<0.0001$ & 0.939 \\
\hline N & 146 & 147 & 67 \\
\hline \multicolumn{4}{|c|}{ p4E cytoplasmic histoscore } \\
\hline Correlation coefficient & 0.329 & 0.427 & 0.147 \\
\hline P-value & $<0.0001$ & $<0.0001$ & 0.252 \\
\hline$N$ & 143 & 144 & 63 \\
\hline \multicolumn{4}{|c|}{ p4E nuclear histoscore } \\
\hline Correlation coefficient & 0.256 & 0.351 & 0.397 \\
\hline$P$-value & 0.002 & $<0.0001$ & 0.001 \\
\hline N & 143 & 144 & 63 \\
\hline \multicolumn{4}{|c|}{$\begin{array}{l}\text { Abbreviations: } 4 E=\text { cytoplasmic and nuclear eukaryotic translation initiation factor } 4 E \text {; } \\
\text { elF4E = eukaryotic translation initiation factor } 4 E ; H S=\text { histoscores; } p 4 E=\text { phosphorylated } \\
\text { eukaryotic translation initiation factor } 4 E \text {. For purposes of analysis each histopathologic } \\
\text { subtype (see Table 1) was given a numerical code. } \\
{ }^{a} \mathrm{HS}=\text { area stained } \times \text { intensity of stain. }\end{array}$} \\
\hline
\end{tabular}

developed later metastases was higher by any measure including raw score, rank or percentile.

Increased eIF4E and phospho-eIF4E expression are associated with reduced survival. The 75th percentiles of staining for eIF4E and phospho-eIF4E expression were chosen a priori as cut-points 
for all Kaplan-Meier analyses to reduce the degrees of freedom associated with survival analyses. A cut-point of 2.7 for cytoplasmic HS for eIF4E was associated with death from melanoma $(P=0.0271)$. An association between nuclear eIF4E expression and melanoma death was not found using a cut-point of 0.9 $(P=0.4994)$. Using the cytoplasmic HS of 2.25 for phospho-eIF4E as a cut-point showed a highly significant association with death $(P=0.0011)$. Nuclear phospho-eIF4E was highly associated with death from melanoma using a cut-point of 0.65 for nuclear HS $(P=0.0042)$.

Using the 75th percentiles of eIF4E expression as cut-points for Kaplan-Meier analysis demonstrated highly significant association for high cytoplasmic eIF4E with poor survival in all patients, and a trend in patients with NM and MM (Figure 3A and B, $P=0.0191$, 0.0573). In contrast, a significant association of high cytoplasmic eIF4E HS with death from melanoma was not found in patients with SSM and LM $(P=0.2250)$. Significant associations between nuclear eIF4E HS $\geqslant 0.9$ and survival were not found (Figure $3 \mathrm{C}$ and D).

Kaplan-Meier analyses demonstrated highly significant associations between high cytoplasmic HS for cytoplasmic phospho-eIF4E and reduced survival in all patients $(P=0.0003)$ and in patients with NM or MM $(P=0.0141)$ (Figure $3 \mathrm{E}$ and $\mathrm{F}$ ) but not with patients with SSM and LM $(P=0.6013)$. High nuclear phosphoeIF4E was highly associated with poor survival in all patients $(P=0.0009)$ and in patients with NM and MM $(P=0.0232)$ (Figure $3 \mathrm{G}$ and $\mathrm{H}$ ). In SSM and LM, high nuclear phospho-eIF4E was not associated with poor survival $(P=0.2252)$.

The Cox proportional HR analyses for phospho-eIF4E expression demonstrated significantly increased HRs in all patients and in patients with NM and MM but not in patients with SSM and LM (Table 3). The $P$-values were adjusted for age in patients with NM and MM and with SSM and LM. The P-values were adjusted for both age and melanoma subtype in the Cox proportional analysis for all patients. The $P$-value (0.7059) for the HR for phospho-eIF4E was not significant, but a piecewise model was significant with low risk up to about an HS of 1.8 then increasing risk above 1.8. The HR for phospho-eIF4E cytoplasmic and nuclear expression were significantly better for SSM and LM (1.13 and 2.00, cytoplasmic and nuclear HRs, respectively) compared with NM and MM (3.66 and 2.93 , cytoplasmic and nuclear $\mathrm{HR}$, respectively) $(P$-value $<0.0001)$. Superficial spreading melanoma had a significantly better $\mathrm{HR}$ compared with all other melanocytic lesions $(P$-value $=0.0007)$. An increased $\mathrm{HR}$ was found for cytoplasmic eIF4E for all patients adjusted for age (HR 2.01, $P$-value $=0.0342)$ but not for NM and MM (HR 2.22, $P$-value $=0.0616)$ or SSM and LM alone (HR 1.45, $P$-value $=0.4936)($ Table 3$)$.

We conclude from these data that increased eIF4E and phosphoeIF4E expression are associated with the development of malignant melanoma, increased risk of metastasis, reduced survival and increased risk of death from melanoma. Even adjusting for confounding factors such as age and subtype of melanoma, the HR for death from melanoma is significantly increased in all patients by increased eIF4E and phospho-eIF4E expression in their tumour.

\section{DISCUSSION}

Numerous reports document the importance of eIF4E in cell transformation, growth of tumours and progression to metastases in epithelial cells and fibroblasts (Pelletier et al, 2015). Because of the limited amount of tissue available, few studies have validated these results in human melanomas. While arising in the skin, melanocytes are derivatives of the neural crest. We believe this is the first report of a detailed analysis of the role of eIF4E and its phosphorylation during the development of human malignant melanoma and progression to metastasis in histopathologic subtypes of melanocytic lesions. This study suggests that eIF4E and phospho-eIF4E are predictive of the malignant potential of melanocytes and are associated with poor clinical outcome including reduced survival and increased risk of death.

eIF4E overexpression in experimental cell models results in only small increases in overall protein synthesis rates while enabling a substantial, disproportionate and selective increase in translation of a subset of mRNAs encoding key proteins involved in critical steps of cancer initiation and progression including cMYC, cyclin D1, ODC, VEGF and others. Very modest changes in expression of eIF4E are required to affect malignancy. Only two- to three-fold increases in eIF4E are sufficient to drive cellular transformation in experimental models (Graff et al, 2008; Hsieh et al, 2012; Pelletier et al, 2015). Here we found a doubling of cytoplasmic eIF4E and a tripling of nuclear eIF4E in melanomas compared with benign nevi (Table 2A). Moreover, both cytoplasmic and nuclear eIF4E were significantly increased in NM and MM, that is, the more lethal lesions (Figure 1E) compared with SSM and LM $(P=0.0087$ and 0.0403, respectively).

The phosphorylation of eIF4E at serine 209 is shown to be essential to the oncogenic function of eIF4E (Topisirovic et al, 2004; Wendel et al, 2007; Furic et al, 2010). Oncogenic RAS markedly increases the rate of eIF4E phosphorylation, and RAS pathway signalling through ERK stimulates the Mnk kinases to phosphorylate eIF4E at serine 209 (Rinkler-Schaeffer et al, 1992; Joshi et al, 1995; Waskiewicz et al, 1999). In experimental models, inhibition of Mnk activity delays tumour development and outgrowth of metastases (Ueda et al, 2010; Konicek et al, 2011). Inhibition of Mnk represses the invasive/mesenchymal phenotype in experimental models of EMT and metastasis (Robichaud et al, 2014).

We found a four-fold increase in cytoplasmic phospho-eIF4E and a nine-fold increase in nuclear phospho-eIF4E in melanomas compared with benign nevi (Table 2A). Thus, phosphorylation of eIF4E was critical to malignant conversion of melanocytes and was significantly increased in the cytoplasm and nucleus of melanocytes in NM and MM relative to SSM and LM $(P=0.0143$ and 0.0044 , respectively).

The association of high levels of nuclear phospho-eIF4E with primary melanomas that metastasised is consistent with the experimental data demonstrating that eIF4E phosphorylation stimulates the translation of prosurvival and proinvasion mRNAs, thereby regulating transforming growth factor- $\beta$-induced EMT (Wendel et al, 2007; Furic et al, 2010; Robichaud et al, 2014). Nuclear localisation of phospho-eIF4E in surgical specimens of NMs and MMs is a novel finding and has no clear explanation, but is prognostic of metastases when found in primary melanomas of all subtypes including SSM, LM and NM. Nuclear localisation of phospho-eIF4E may have utility as a marker for metastatic potential in malignant melanoma as well as be an adverse prognostic factor for survival.

Our data suggest that targeting eIF4E or eIF4E phosphorylation may be an attractive therapeutic strategy in malignant melanoma. Targeting eIF4E function with an ASO against eIF4E (LY2275796) was tested in cell lines and in xenograft models with promising activity (Graff et al, 2007). Translation of known eIF4E-specific progrowth and prosurival gene products was reduced by LY2275796, whereas global protein synthesis was only modestly affected. A phase 1 trial showed that LY2275796 could be safely administered to patients and was effective at decreasing eIF4E mRNA and protein levels in tumour cells (Hong et al, 2011). Since elevated eIF4E is associated with resistance to doxorubicin, rapamycin, $\mathrm{PI} 3 \mathrm{~K} / \mathrm{mTOR}$ kinase inhibitors and anti-BRAF or anti-MEK therapies (Wendel et al, 2004, 2006; Ilic et al, 2011; Boussemart et al, 2014; Cope et al, 2014), LY2275796 may act 
A
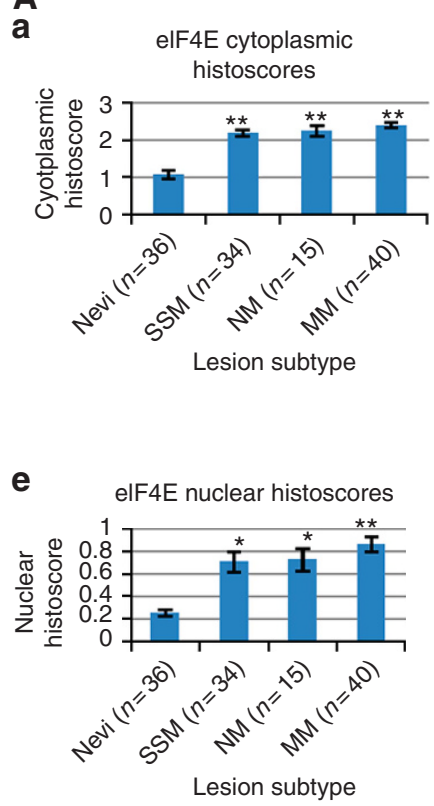

B

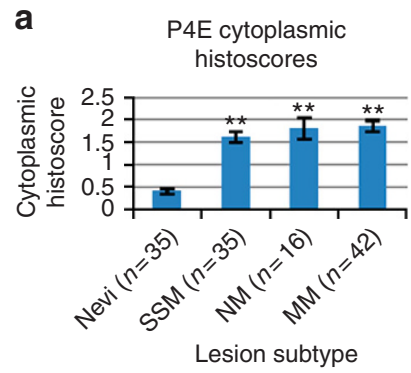

e

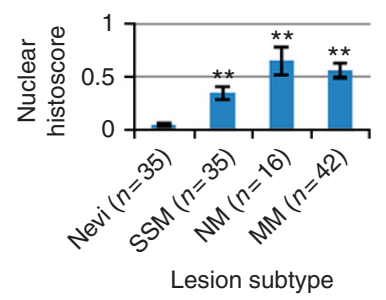

b

Benign nevus

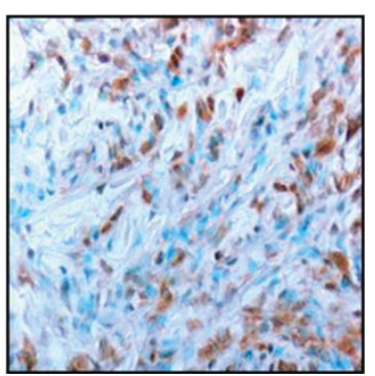

f

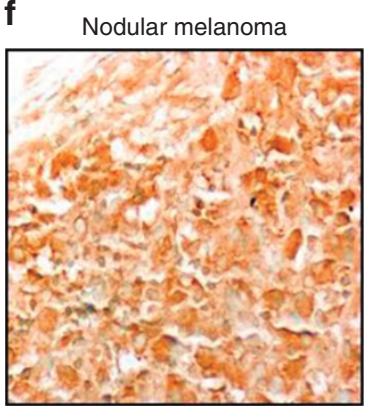

b
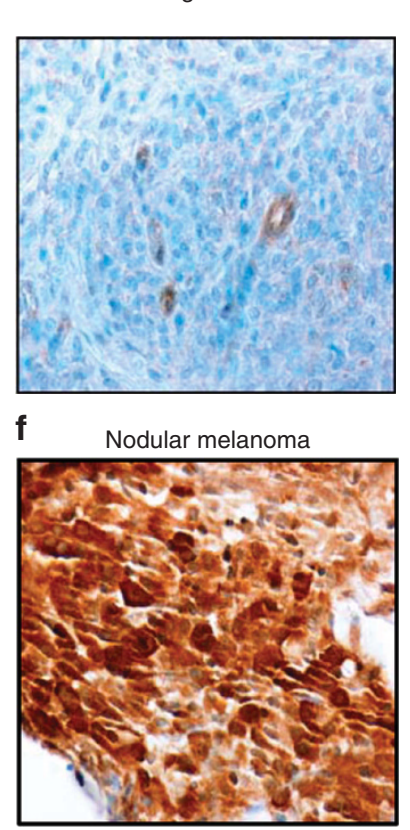

C

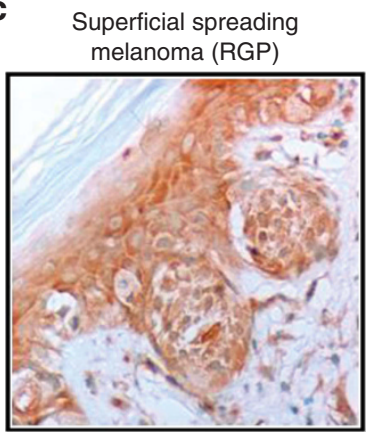

g

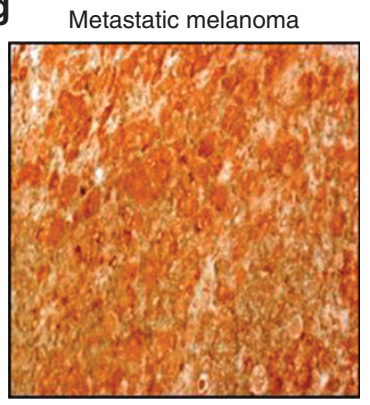

C

Superficial spreading melanoma (RGP)
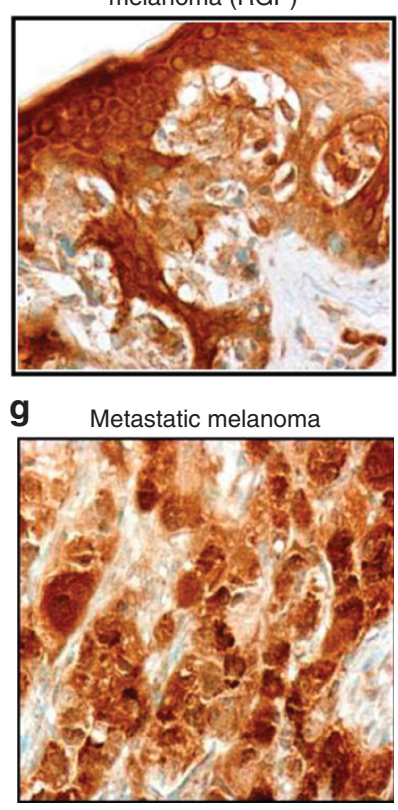

d

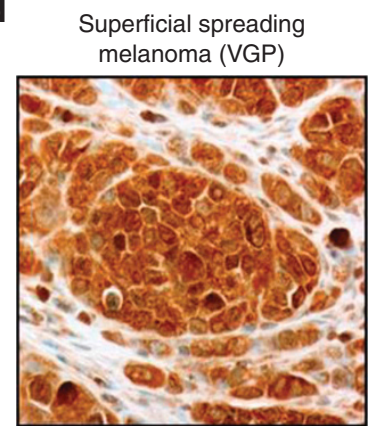

h

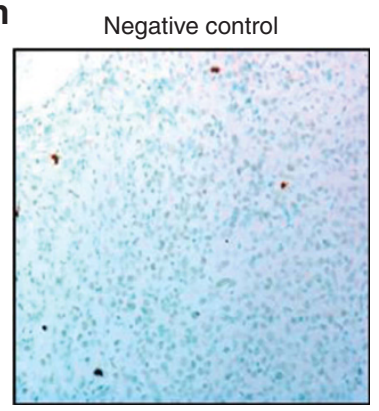

d

Superficial spreading melanoma (VGP)

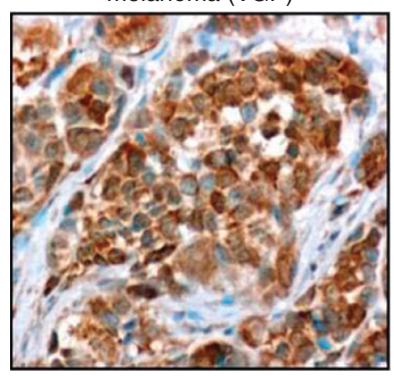

h

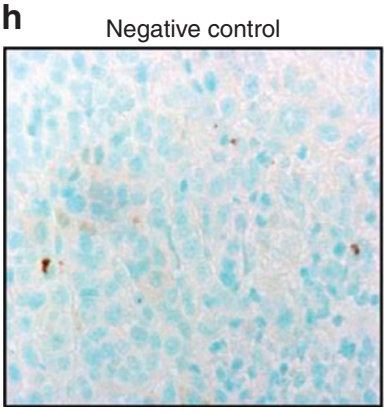

Figure 2. (A) Eukaryotic translation initiation factor $4 \mathrm{E}$ cytoplasmic and nuclear stain in melanocytic lesions. (a) Eukaryotic translation initiation factor 4E cytoplasmic HS (area stained $\times$ stain intensity) are increased in malignant melanomas compared with benign nevi $(P$-value $<0.0001)$. (b) Eukaryotic translation initiation factor $4 \mathrm{E}$ stain in benign nevus. Note scattered lightly stained cells, $\times 400$. (c) Eukaryotic translation initiation factor 4E stain in SSM, RGP, $\times 400$. (d) Eukaryotic translation initiation factor 4E stain in SSM, VGP. Note intense and uniform stain in the lesion, $\times$ 400. (e) Eukaryotic translation initiation factor $4 \mathrm{E}$ nuclear HS are increased in malignant melanomas compared with benign nevi $(P$-value $<0.0001$ ). (f) Uniform cytoplasmic stain in an NM for elF4E, $\times 400$. (g) Intense uniform cytoplasmic staining for elF4E in MM, $\times 400$. (h) Metastatic melanoma, mouse lgG2B-negative control, $\times$ 400. (B) Phosphorylated elF4E cytoplasmic and nuclear stain in melanocytic lesions. (a) Phosphorylated elF4E (phospho-elF4E) cytoplasmic HS are increased in malignant melanomas compared with benign nevi ( $P$-value $<0.0001$ ). (b) Phospho-elF4E stain in benign nevus. Nevus is devoid of significant stain, $\times 400$. (c) Phospho-elF4E stain in SSM, RGP. Note less stain in SSM compared with the adjacent skin, $\times$ 400. (d) Phospho-elF4E stain in SSM, VGP, $\times 400$. (e) Phospho-elF4E nuclear HS are increased in malignant melanomas compared with benign nevi ( $P$-value $<0.0001)$. (f) Uniform intense cytoplasmic and nuclear stain in an NM for phospho-elF4E, $\times$ 400. (g) Uniform intense cytoplasmic and nuclear staining for phospho-elF4E in MM, $\times 400$. (h) Metastatic melanoma, rabbit lgG negative control, $\times 400$. 
A

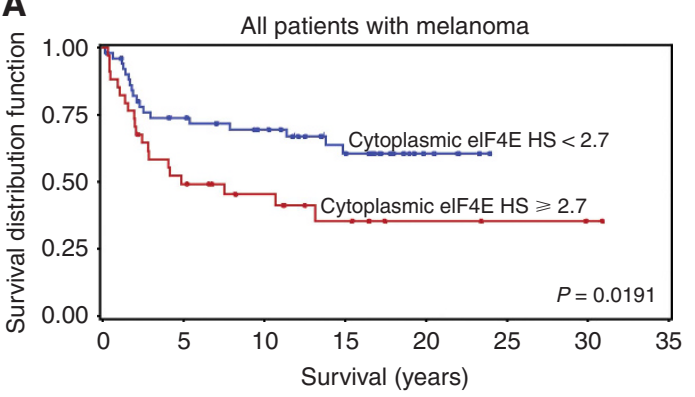

\section{C}

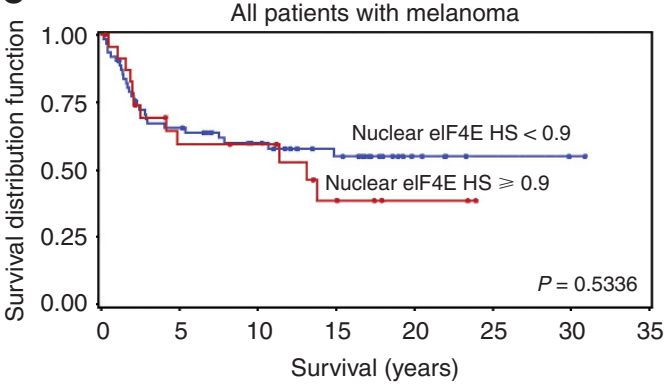

E

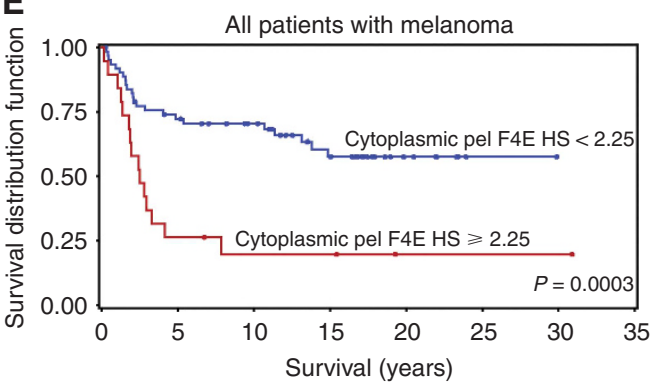

G

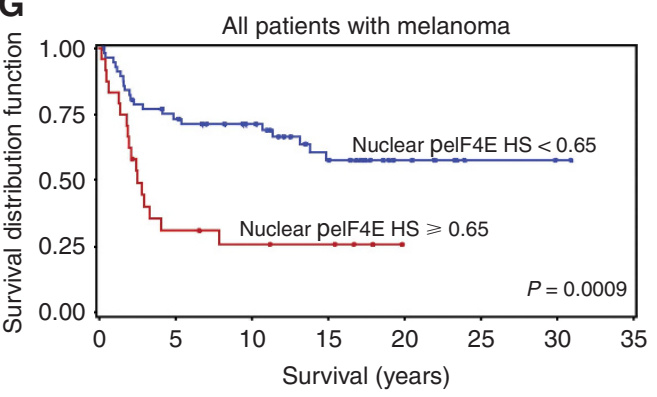

B

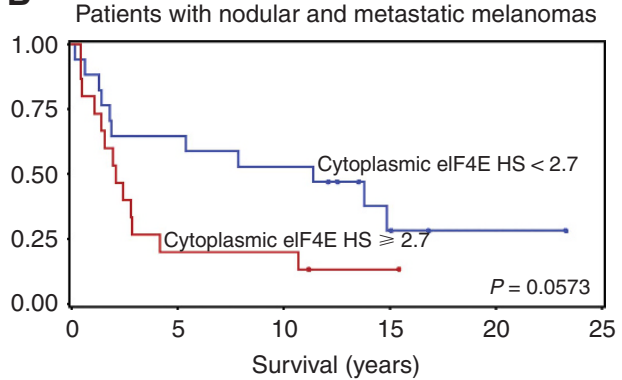

D

Patients with nodular and metastatic melanomas

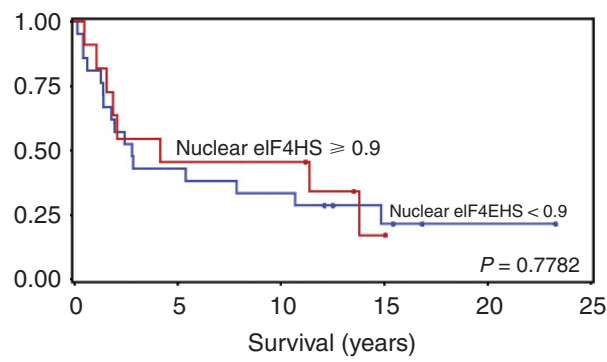

$\mathbf{F}$

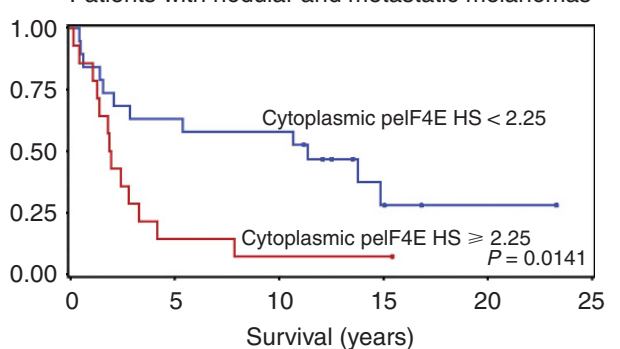

H

Patients with nodular and metastatic melanomas

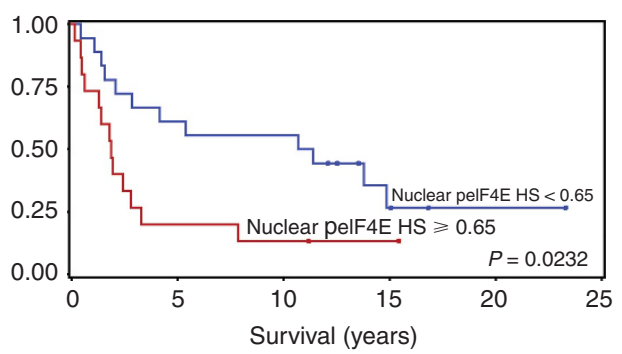

Figure 3. Kaplan-Meier curves of patient survival according to cytoplasmic eukaryotic translation initiation factor $4 \mathrm{E}$ and cytoplasmic and nuclear phospho-elF4E expression in melanocytic histopathologic subtypes. Significant differences in survival were not found with nuclear elF4E. Cutoff values chosen a priori were the 75th percentile of each marker. (A) Patients with any form of melanoma who have at or above the 75th percentile of cytoplasmic elF4E expression have reduced survival. (B) Patients with NM or MM who have at or above the 75th percentile of cytoplasmic elF4E expression have a reduced survival trend. (C) Patients with any form of melanoma who have at or above the 75th percentile of nuclear elF4E expression do not have reduced survival. (D) Patients with NM or MM who have at or above the 75th percentile of nuclear elF4E expression do not have reduced survival. (E) Patients with any form of melanoma who have at or above the 75th percentile of cytoplasmic phospho-elF4E expression have reduced survival. (F) Patients with NM or MM who have at or above the 75th percentile of cytoplasmic phospho-elF4E expression have reduced survival. (G) Patients with any form of melanoma who have at or above the 75th percentile of nuclear phospho-elF4E expression have reduced survival. (H) Patients with NM or MM who have at or above the 75th percentile of nuclear phospho-elF4E expression have reduced survival.

synergistically to increase the efficacy of these treatments or to overcome resistance. In mesothelioma cells, eIF4E knockdown with LY2275796 results in decreased expression of antiapoptotic and progrowth proteins and enhances chemosensitivity to cytarabine (Jacobson et al, 2013).

In our study, increased phospho-eIF4E was strongly associated with a marked reduction in survival and an increase in the HR for death from melanoma. Coupled to the wealth of data implicating activation of the ras-raf-ERK-MEK-MNK pathway signalling in metastatic melanoma (Bastian, 2014), inhibiting eIF4E phosphorylation may be another promising therapeutic strategy for malignant melanoma. Indeed, increased $4 \mathrm{E}$ phosphorylation has been specifically associated with the expression of the oncogene BRAF $^{\mathrm{V} 600 \mathrm{E}}$ in melanocytes (Croft et al, 2014). Blocking eIF4E phosphorylation prevents the oncogenic function of eIF4E in multiple experimental models (Wendel et al, 2007; Furic et al, 
Table 3. Determination of the HRs for death from melanoma ${ }^{a}$ using the Cox proportional hazards model: (A) patient outcome and (B) P-values and HRs

(A) Patient outcomes

\begin{tabular}{|l|c|c|c|}
\hline Histopathologic subtype & Dead & Alive & Total \\
\hline Superficial spreading melanoma & 7 & 27 & 34 \\
\hline Nodular melanoma & 12 & 4 & 14 \\
\hline Acral lentiginous melanoma & 2 & 8 & 11 \\
\hline Lentigo maligna melanoma & 3 & 1 & 3 \\
\hline Mucosal lentiginous melanoma & 2 & 6 & 20 \\
\hline Metastatic melanoma & 14 & & 6 \\
\hline
\end{tabular}

(B) P-values and HRs

\begin{tabular}{|c|c|c|c|c|c|c|c|c|c|c|}
\hline Histopathologic subtype & $\begin{array}{c}\text { Nodular and } \\
\text { metastatic } \\
\text { melanomas } \\
P \text {-value }\end{array}$ & HR & $\begin{array}{c}\text { Superficial } \\
\text { spreading and } \\
\text { lentiginous } \\
\text { melanomas } \\
P \text {-value }\end{array}$ & HR & $\begin{array}{c}\text { All } \\
\text { melanomas } \\
P \text {-value }\end{array}$ & HR & $\begin{array}{c}\text { All } \\
\text { melanomas } \\
P \text {-value }\end{array}$ & HR & $\begin{array}{c}\text { All melanomas } \\
P \text {-value }\end{array}$ & HR \\
\hline Age & 0.5222 & 0.99 & 0.0044 & 1.07 & 0.0319 & 1.03 & 0.0785 & 1.02 & & \\
\hline elF4E cytoplasmic histoscore & 0.0616 & 2.22 & 0.4936 & 1.45 & 0.0342 & 2.01 & 0.0257 & 2.09 & 0.0323 & 2.03 \\
\hline elF4E nuclear histoscore & 0.8542 & 0.92 & 0.6083 & 1.36 & 0.6714 & 1.16 & 0.9856 & 1.01 & 0.836 & 0.93 \\
\hline p4E cytoplasmic histoscore & 0.0052 & 3.66 & 0.8992 & 1.13 & 0.0031 & 2.78 & 0.0217 & 2.24 & 0.0555 & 2.01 \\
\hline p4E nuclear histoscore & 0.0134 & 2.93 & 0.2533 & 2.00 & 0.0049 & 2.56 & 0.0132 & 2.31 & 0.0307 & 2.11 \\
\hline Adjusted & Age & & Age & & Age & & Lesion subtype & & Age, lesion subtype & \\
\hline
\end{tabular}

2010; Konicek et al, 2011), suggesting that pharmacologic inhibition of the Mnk kinases may be a promising therapeutic strategy. The Mnk inhibitors CGP57380 and cercosporamide block eIF4E phosphorylation in cultured cells limiting cellular proliferation in large part by inducing apoptosis (Tschopp et al, 2000; Knauf et al, 2001; Konicek et al, 2011). Inducing apoptosis may be an 'Achilles' heel' for melanomas, which are known to be resistant to apoptosis (Soengas and Lowe, 2003). Oral administration of cercosporamide suppressed eIF4E phosphorylation in normal mouse tissues and xenograft tumour tissues and profoundly suppressed the outgrowth of B16 melanoma metastases (Konicek et al, 2011). Cercosporamide treatment at doses that inhibited eIF4E phosphorylation decreased the growth rate of acute myeloid leukaemia (AML) xenografted tumours and suppressed colonisation of freshly explanted AML patient samples (Altman et al, 2013). Moreover, cercosporamide enhanced the antileukaemic effects of cytarabine in vitro and in vivo, suggesting the potential efficacy of combining Mnk inhibitors with other drugs.

Whichever approach is taken, inhibition of either eIF4E or eIF4E phosphorylation, the near uniform expression of these proteins in malignant melanocytes as seen in Figure 2 suggests that either approach may overcome tumour heterogeneity that can result in the selection of resistant malignant melanocytes, malignant progression and therapeutic failure (Ramon et al, 2014).

\section{ACKNOWLEDGEMENTS}

We thank Cathy Reising, BBA, CTR, the staff of the Esther Marie Hatton Tumour Registry and the Department of Laboratory Medicine at St Elizabeth Healthcare for their invaluable assistance. This work was supported by a Research Agreement between Eli Lilly and Company and Julia $\mathrm{H}$ Carter, $\mathrm{PhD}$, Wood Hudson Cancer Research Laboratory Inc. (a not-for-profit research institute). Jeremy $\mathrm{R}$ Graff, $\mathrm{PhD}$, was an employee of Eli Lilly and Company.

\section{CONFLICT OF INTEREST}

The authors declare no conflict of interest.

\section{REFERENCES}

Altman JK, Szilard A, Konicek BW, Iversen PW, Kroczynska B, Glaser H, Sassano A, Vakana E, Graff JR, Platanias LC (2013) Inhibition of Mnk kinase activity by cercosporamide and suppressive effects on acute myeloid leukemia precursors. Blood 121: 3675-3681.

Bastian BC (2014) The molecular pathology of melanoma: an integrated taxonomy of melanocytic neoplasia. Annu Rev Pathol 9: 239-271.

Boussemart L, Malka-Mahieu H, Girault I, Allard D, Hemmingsson O, Tomasic G, Thomas M, Basmadjian C, Ribeiro N, Thuaud F, Mateus C, Routier E, Kamsu-Kom N, Agoussi S, Eggermont AM, Desaubry L, Robert C, Vagner S (2014) eIF4F is a nexus of resistance to anti-BRAF and anti-MEK cancer therapies. Nature 513: 105-109.

Chin L, Merlino G, DePinho RA (1998) Malignant melanoma: modern black plague and genetic black box. Genes Dev 12: 3467-3481.

Cope CL, Gilley R, Balmanno K, Sale MJ, Howarth KD, Hampson M, Smith PD, Guichard SM, Cook SJ (2014) Adaptation to mTOR kinase inhibitors by amplification of eIF4E to maintain cap-dependent translation. J Cell Sci 127: 788-800.

Croft A, Tay KH, Boyd SC, Guo ST, Jiang CC, Lai F, Tseng HY, Jin L, Rizos H, Hersey P, Zhang XD (2014) Oncogenic activation of MEK/ERK primes melanoma cells for adaptation to endoplasmic reticulum stress. J Invest Dermatol 134: 488-497.

Duband JL, Monier F, Delannet M, Newgreen D (1995) Epithelium-mesenchyme transition during neural crest development. Acta Anat 154: 63-78.

Elder DE, Murphy GF (2010) Melanocytic Tumors of the Skin (AFIP Atlas of Tumor Pathology, Fourth Series Fascicle). American Registry of Pathology: Washington DC, USA.

Furic L, Rong L, Larsson O, Koumakpayi IH, Yoshida K, Brueschke A, Petroulakis E, Robichaud N, Pollak M, Gaboury LA, Pandolfi PP, Saad F, Sonenberg N (2010) eIF4E phosphorylation promotes tumorigenesis and is associated with prostate cancer progression. Proc Natl Acad Sci USA 107: 14134-14139. 
Gilbert SF (2000) Developmental Biology, 6th edn. Sinauer Associates: Sunderland, MA, USA.

Gingras AC, Gygi SP, Raught B, Polakiewicz RD, Abraham RT, Hoekstra MF, Aebersold R, Sonenberg N (1999) Regulation of 4E- BP1 phosphorylation: a novel two-step mechanism. Genes Dev 13: 1422-1437.

Graff JR, Boghaert ER, De Benedetti A, Tudor DI, Zimmer CC, Chan SK, Zimmer SG (1995) Reduction of translation initiation factor 4E decreases the malignancy of ras-transformed cloned rat embryo fibroblasts. Int J Cancer 60: 255-263.

Graff JR, Konicek BW, Carter JH, Marcusson EG (2008) Targeting the eukaryotic translation initiation factor $4 \mathrm{E}$ for cancer therapy. Cancer Res 68: 631-634.

Graff JR, Konicek BW, Lynch RL, Dumstorf CA, Dowless MS, McNulty AM, Parsons SH, Brail LH, Colligan BM, Koop JW, Hurst BM, Deddens JA, Neubauer BL, Stancato LF, Carter HW, Douglass LE, Carter JH (2009) eIF4E activation is commonly elevated in advanced human prostate cancers and significantly related to reduced patient survival. Cancer Res 69: $3866-3873$.

Graff JR, Konicek BW, Vincent TM, Lynch RL, Monteith D, Weir SN, Schwier P, Capen A, Goode RL, Dowless MS, Chen Y, Zhang H, Sissons S, Cox K, McNulty AM, Parsons SH, Wang T, Sams L, Geeganage S, Douglass LE, Neubauer BL, Dean NM, Blanchard K, Shou J, Stancato LF, Carter JH, Marcusson EG (2007) Therapeutic suppression of translation initiation factor eIF4E expression reduces tumor growth without toxicity. J Clin Invest 117: 2638-2648.

Gray-Schopfer V, Wellbrock C, Marais R (2007) Melanoma biology and new targeted therapy. Nature 445: 851-857.

Haqq C, Nosrati M, Sudilosvsky D, Crothers J, Khodabakhsh D, Pulliam BL, Federman S, Miller 3rd JR, Allen RE, Singer MI, Leong SP, Ljung BM, Sagebiel RW, Kashani-Sabet M (2005) The gene expression signatures of melanoma progression. Proc Natl Acad Sci USA 102: 6092-6097.

Hong DS, Kurzrock R, Oh Y, Wheler J, Naing A, Brail L, Callies S, Andre V, Kadam SK, Nasir A, Holzer TR, Meric-Bernstam F, Fishman M, Simon G (2011) A phase I dose escalation, pharmacokinetic, and pharmacodynamic evaluation of eIF-4E antisense oligonucleotide Ly2275796 in patients with advanced cancer. Clin Cancer Res 17: 6582-6591.

Hsieh AC, Liu V, Edlin MP, Ingolia NT, Janes MR, Sher A, Shi EY, Stumpf CR, Christensen C, Bonham MJ, Wang S, Ren P, Martin M, Jessen K, Feldman ME, Weissman JS, Shokat KM, Rommel C, Ruggero D (2012) The translational landscape of mTOR signalling steers cancer initiation and metastasis. Nature 485: 55-61.

Ilic N, Utermark T, Widlund HR, Roberts TM (2011) PI3K-targeted therapy can be evaded by gene amplification along the MYC-eukaryotic translation initiation factor 4E (eIF4E) axis. Proc Natl Acad Sci USA 108: 699-708.

Jacobson BA, Thumma SC, Jay-Dixon J, Patel MR, Kroening KD, Kratzke MG, Etchison RG, Konicek BW, Graff JR, Kratzke RA (2013) Targeting eukaryotic translation in mesothelioma cells with an eIF4E-specific antisense oligonucleotide. PLoS One 8: 1-11.

Jaeger J, Koczan D, Thiesen H-J, Ibrahim SM, Gross G, Spang R, Kunz M (2007) Gene expression signatures for tumor progression, tumor subtype, and tumor thickness in laser-microdissected melanoma tissues. Clin Cancer Res 13: 806-815.

Joshi B, Cai AL, Keiper BD, Minich WB, Mendez R, Beach CM, Stepinski J, Stolarski R, Darzynkiewicz E, Rhoads RE (1995) Phosphorylation of eukaryotic protein synthesis initiation factor 4E at Ser-209. J Biol Chem 270: 14597-14603.

Knauf U, Tschopp C, Gram H (2001) Negative regulation of protein translation by mitogen-activated protein kinase-interacting kinases 1 and 2. Mol Cell Biol 21: 5500-5511.

Konicek BW, Stephens JR, McNulty AM, Robichaud N, Peery RB, Dumstorf CA, Dowless MS, Iversen PW, Parsons S, Ellis KE, McCann DJ, Pelletier J, Furic L, Yingling JM, Stancato LF, Sonenberg N, Graff JR (2011) Therapeutic inhibition of MAP kinase interacting kinase blocks eukaryotic initiation factor $4 \mathrm{E}$ phosphorylation and suppresses outgrowth of experimental lung metastases. Cancer Res 71: 1849-1857.

Lian CG, Mihm MC Jr (2014) Skin cancer. In: World Cancer Report 2014, Stewart BW, Wild CP (eds). International Agency for Research on Cancer World Health Organization: Lyon, France, pp 495-502.
Linos E, Swetter SM, Cockburn MG, Colditz GA, Clarke CA (2009) Increasing burden of melanoma in the United States. J Invest Dermatol 129: $1666-1674$.

O'Reilly KE, Warycha M, Davies MS, Rodrik V, Zhou XK, Yee H, Polsky D, Pavlick AC, Rosen N, Bhardwaj N, Mills G, Osman I (2009) Phosphorylated 4E-BP1 is associated with poor survival in melanoma. Clin Cancer Res 15: 2872-2878.

Pelletier J, Graff J, Ruggero D, Sonenberg N (2015) Targeting the eIF4F translation initiation complex: a critical nexus for cancer development. Cancer Res 75: 250-263.

Ramon YCS, De Mattos-Arruda L, Sonenberg N, Cortes J, Peg V (2014) The intra-tumor heterogeneity of cell signaling factors in breast cancer: p4E-BP1 and peIF4E are diffusely expressed and are real potential targets. Clin Tranl Oncol 16: 937-941.

Rinkler-Schaeffer CW, Austin V, Zimmer S, Rhoads RF (1992) Ras transformation of cloned rat fibroblasts results in increased rates of protein synthesis and phosphorylation of eukaryotic initiation factor $4 \mathrm{E}$. J Biol Chem 267: 10659-10664.

Robichaud N, Del Rincon SV, Huor B, Alain T, Petruccelli LA, Hearnden J, Goncalves C, Grotegut S, Spruck CH, Furic L, Larsson O, Muller WJ, Miller WH, Sonenberg N (2014) Phosphorylation of eIF4E promotes EMT and metastasis via translational control of SNAIL and MMP-3. Oncogene 34: 2032-2042.

Siegel R, Ma J, Zou Z, Jemal A (2014) Cancer Statistics, 2014. Ca Cancer J Clin 64: 9-29.

Silvera D, Formenti SC, Schneider RJ (2010) Translational control in cancer. Nat Rev Cancer 10: 264-266.

Soengas MS, Lowe SW (2003) Apoptosis and melanoma chemoresistance. Oncogene 22: 3138-3151.

Topisirovic I, Ruiz-Gutierrez M, Borden KL (2004) Phosphorylation of the eukaryotic translation initiation factor eIF4E contributes to its transformation and mRNA transport activities. Cancer Res 64: 8639-8642.

Tschopp C, Knauf U, Brauchle M, Zurini M, Ramage P, Glueck D, New L, Han J, Gram H (2000) Phosphorylation of eIF-4E on Ser 209 in response to mitogenic and inflammatory stimuli is faithfully detected by specific antibodies. Mol Cell Biol Res Commun 3: 205-211.

Ueda T, Sasaki M, Elia AJ, Chio, Hamada K, Fukunaga R, Mak TW (2010) Combined deficiency for MAP kinase-interacting kinase 1 and 2 (Mnk1 and Mnk2) delays tumor development. Proc Natl Acad Sci USA 107: 13984-13990.

Waskiewicz AJ, Johnson JC, Penn B, Mahalingam M, Kimball SR, Cooper JA (1999) Phosphorylation of the cap-binding protein eukaryotic translation initiation factor $4 \mathrm{E}$ by protein kinase Mnk1 in vivo. Mol Cell Biol 19: 1871-1880.

Wendel HG, de Stanchina E, Fridman JS, Malina A, Ray S, Kogan S, Cordon-Cardo C, Pelletier J, Lowe SW (2004) Survival signalling by Akt and eIF4E in oncogenesis and cancer therapy. Nature 428: 332-337.

Wendel HG, Malina A, Zhao Z, Zender L, Kogan SC, Cordon-Cardo C, Pelletier J, Lowe SW (2006) Determinants of sensitivity and resistance to rapamycin-chemotherapy drug combinations in vivo. Cancer Res 66: 7639-7646.

Wendel HG, Silva RL, Malina A, Mills JR, Zhu H, Ueda T, Watanabe-Fukunaga R, Fukunaga R, Terua-Feldstein J, Pelletier J, Lowe SW (2007) Dissecting eIF4E action in tumorigenesis. Genes Dev 21 : 3232-3237.

Zhan Y, Dahabieh MS, Rajakumar A, Dobocan MC, M’Boutchou MN, Goncalves C, Shiru LL, Pettersson F, Topisirovic I, ven Kempen L, Del Rincon SV, Miller WH Jr (2015) The role of eIF4E in response and acquired resistance to vemurafenib in melanoma. J Invest Dermatol 135: 1368-1376.

This work is published under the standard license to publish agreement. After 12 months the work will become freely available and the license terms will switch to a Creative Commons AttributionNonCommercial-Share Alike 4.0 Unported License. 